\title{
Review
}

Neonatology

\section{Brain-Sparing in Intrauterine Growth Restriction: Considerations for the Neonatologist}

\author{
Emily Cohen $^{\mathrm{a}, \mathrm{b}}$ Willem Baerts ${ }^{\mathrm{a}}$ Frank van Bel $^{\mathrm{a}}$ \\ ${ }^{a}$ Department of Neonatology, Wilhelmina Children's Hospital/Utrecht University Medical Centre, Utrecht, \\ The Netherlands; ${ }^{b}$ The Ritchie Centre, Hudson Institute of Medical Research and Department of Paediatrics, \\ Monash University, Melbourne, Vic., Australia
}

\section{Key Words}

Intrauterine growth restriction . Small for gestational age . Brain-sparing $\cdot$ Cerebral circulation

\begin{abstract}
Intrauterine growth restriction (IUGR) is most commonly caused by placental insufficiency, in response to which the fetus adapts its circulation to preserve oxygen and nutrient supply to the brain ('brain-sparing'). Currently, little is known about the postnatal course and consequences of this antenatal adaptation of the cerebral circulation. The altered cerebral haemodynamics may persist after birth, which would imply a different approach with regard to cerebral monitoring and clinical management of IUGR preterm neonates than their appropriately grown peers. Few studies are available with regard to this topic, and the small body of evidence shows controversy. This review discusses the cerebral circulatory adaptations of IUGR fetuses and appraises the available literature on their postnatal cerebral circulation with potential clinical consequences.

(C) 2015 S. Karger AG, Basel
\end{abstract}

\section{Introduction}

Intrauterine growth restriction (IUGR) is traditionally and most commonly defined as a birth weight below the 10th percentile for gestational age on the appropriate population growth curve. IUGR is most commonly caused by placental insufficiency, in response to which the fetus adapts its circulation to preserve oxygen and nutrient supply to the brain ('brain-sparing'). The altered cerebral haemodynamics may persist after birth, which would imply a different approach with regard to cerebral monitoring and clinical management of IUGR preterm neonates than their appropriately grown (AGA) peers. This review discusses the cerebral circulatory adaptations of IUGR fetuses and appraises the available literature on the postnatal consequences of this phenomenon.

\section{Brain-Sparing in the Compromised Fetus}

In the situation of chronic fetal hypoxaemia or nutrient deprivation, the fetus redistributes its cardiac output to maximise oxygen and nutrient supply to the brain (brain-sparing). The fetal circulation is a parallel circuit where the majority of the right ventricular output is shunted through the ductus arteriosus to the descending aorta, and the left ventricle mainly supplies the upper 
body and the brain. Vasoconstriction of peripheral vascular beds leads to an increase of the right ventricular afterload. In the case of placental insufficiency, raised placental vascular resistance contributes to this increased systemic resistance [1]. On the other hand, vasodilation of the cerebral arteries causes a decrease in left ventricular afterload. These changes result in a preferential shift of the cardiac output in favour of the left ventricle, enhancing blood supply towards the brain [2].

\section{Regional Rather than Global Redistribution}

It is now believed that brain-sparing occurs regionally rather than globally throughout the brain. HernandezAndrade et al. [3] have shown by measuring fractional moving blood volume (FMBV) that cerebral blood flow $(\mathrm{CBF})$ in IUGR fetuses shows regional changes with progression of fetal deterioration. They saw an initial increase in frontal FMBV, followed by a decrease as fetal condition worsened. Basal ganglia FMBV, on the other hand, showed a steady and significant increase with fetal deterioration. The cerebellum showed a similar trend of FMBV increase related to the severity of fetal compromise. An increase in cerebellar FMBV may also imply enhanced blood supply to the brainstem, as both are fed through the posterior cerebral circulation. The results of their study suggest a hierarchical order in cerebral blood supply in case of chronic hypoxia. At earlier stages, higher cognitive functions of the frontal lobes are protected; however, under chronic and more threatening circumstances the focus seems to shift towards survival, protecting important structures such as the basal ganglia and the brainstem [3].

\section{Detection of Brain-Sparing}

Changes in $\mathrm{CBF}$ associated with brain-sparing can be detected by Doppler sonography. Cerebral vasodilation and thus lowered cerebral vascular resistance lead to increased end-diastolic flow velocity in the cerebral arteries. As a result, it is believed that cerebral vasodilation and increased CBF can be detected by a decrease in the pulsatility index [PI; (peak systolic flow velocity - end-diastolic flow velocity)/time averaged flow velocity] or resistance index [RI; (peak systolic flow velocity - end-diastolic flow velocity)/peak systolic flow velocity] of the cerebral arteries. The middle cerebral artery (MCA) is used as the gold standard and a MCA-PI below the 5th percentile is generally classified as abnormal [4]. As blood flow redistribution has been shown to occur in a regional manner [3], brain-sparing may be present before it can be detected by an abnormal MCA-PI [5]. Several studies have reported $\mathrm{CBF}$ changes in the anterior cerebral artery to occur more frequently and earlier than changes in the MCA [6-8]. This is in line with the theory of hierarchical CBF redistribution: initially protecting higher cognitive functions of the frontal lobes which are supplied by the anterior cerebral artery, followed by more elementary brain regions such as the basal ganglia, which are supplied by the MCA.

A number of authors have proposed that the calculation of the cerebroplacental ratio (CPR) is of additional value to diagnose brain-sparing [9-16]. This ratio between the MCA and UA-PI or -RI can be decreased, while the individual values remain within normal limits. Some authors have indicated that the CPR has a higher sensitivity than the MCA alone to predict perinatal and neonatal outcome $[9,11]$. Of these studies, however, many showed that fetuses with an abnormal CPR were born more prematurely $[9,10,12]$, which may have confounded their results.

\section{Reversal of Compensatory Flow}

There have been reports of severely compromised IUGR fetuses displaying a return of the MCA-PI towards normal values [17-19]. This reversal of compensatory flow is thought to be a pre-terminal sign. In fact, in a report by Konje et al. [17], 4 out of 8 fetuses that showed MCA normalisation were subsequent stillbirths, and the other 4 died during the neonatal period. It is not fully understood as to why this reversal of compensatory flow occurs, and the cause may be multifactorial. It has been proposed that chronic hyperperfusion of the fetal brain leads to cerebral oedema, compromising CBF [19]. A decrease in CBF may also be a result of fetal cardiac decompensation [17]. Theoretically, this could be due to reduced cardiac output [17], but is more likely to result from venous congestion. In support of this hypothesis, postmortem cerebral examination of an IUGR fetus that succumbed following normalisation of CBF revealed not only marked dilatation of the MCA, but also periventricular radial congestion [18]. Periventricular congestion is thought to be of venous origin related to congestion of the vein of Galen [20,21]. Enhanced blood flow in the vein of Galen, indicating increased venous return due to brain-sparing, has been reported in IUGR fetuses [22]. Under normal conditions blood flow within this vein does not show pulsations [23], but pulsatility has been described in pregnancies complicated by hypertension and IUGR [22, 23]. These pulsations are thought to result from transmission of pressure waves from the venous circulation [23], which in turn are believed to represent fetal heart failure [24]. In conclusion, fetal heart failure may compromise venous cerebral return, which subsequently may compromise brain-sparing. 


\section{Potential Consequences of Prolonged Brain-Sparing}

Brain-sparing is in essence a protective mechanism under chronic hypoxaemia; however, prolonged brainsparing may lead to an altered structure and function of the cerebral vasculature.

\section{Cerebrovascular Remodelling}

Signs of vascular remodelling of systemic arteries have been found in both human and animal studies of IUGR [25-34]. It is thought that this vascular remodelling process is caused by the systemic haemodynamic changes seen in IUGR, which alter shear stress and wall tension [35]. It is therefore plausible that similar vascular wall changes occur in the cerebral vessels since brain-sparing has great impact on the cerebral haemodynamics. In fact, increased incidence of stroke has been reported in adults born with low birth weight [36]. Although low birth weight is related to other risk factors for stroke such as hypertension [37], the association between low birth weight and stroke was most pronounced for individuals with low birth weight and low placental weight in relation to head size [36]. The relative increased head size suggests that brain-sparing was present in these individuals and may have made them more susceptible to the occurrence of stroke [38]. However, very little research has been conducted in this area. Animal models of pregnant sheep using high altitude as a means to induce fetal hypoxia have demonstrated changes in vascular wall composition and contractility [39]. It has been suggested that these vascular adaptations to chronic hypoxia help preserve energy while still maintaining basic contractile function [40]. Although remodelling may help preserve energy under detrimental intrauterine circumstances, the postnatal implications of these adaptations have not been well investigated. In fact, a recent study demonstrated compromised structural integrity and stability of the cerebral microvasculature in IUGR lambs, increasing the blood-brain barrier permeability and their risk for cerebral haemorrhages [41].

\section{Loss of Cerebral Vasoreactivity}

Prolonged brain-sparing and vascular remodelling may lead to reduced vascular wall function. Prenatal loss of vasoreactivity in IUGR has been suggested by a study where human IUGR fetuses with brain-sparing were exposed to maternal hyperoxygenation. A subset of these fetuses did not show the expected rise in cerebral resistance in response to the increased oxygen levels. The finding that these fetuses did not adjust their cerebral circulation to the new situation is suggestive of impaired cerebrovascular regulation. These 'non-responders' were also found to have a higher risk of being delivered for fetal distress and the interval between the Doppler examination and delivery was shorter compared to the 'responders', indicating that they were more compromised [42]. Impaired vasoreactivity may also be another explanation as to why loss of compensatory brain-sparing - as described previously can eventually occur. The case illustrated by Fignon et al. [18] showed that the cerebral RI and the CPR ceased to show normal physiological fluctuations, indicative of the loss of vascular reactivity, before the RI and CPR eventually rose and compensation of flow was reversed. If impaired vasoreactivity persists after birth, it can compromise cerebral autoregulation, which is an important mechanism to prevent cerebral hypo- and hyperperfusion.

\section{Postnatal Cerebral Circulation following Brain-Sparing}

Currently, little is known about the postnatal cerebral circulation of IUGR neonates. The small body of evidence available in the literature indicates that the altered cerebral haemodynamics that exist before birth persist postnatally. Similarly to prenatal Doppler observations, lower PI and RI of the MCA and anterior cerebral artery have been found up to 4 days postnatal age, indicating persistent dilatation of the cerebral arteries [43-45]. In agreement with these findings, increased $\mathrm{CBF}$ as measured by Xenon-133 has also been reported on the first day of life [46]. Moreover, higher regional cerebral oxygen saturation and reduced cerebral oxygen extraction have been reported within the first $24 \mathrm{~h}$ of birth [47]. All of these cerebral haemodynamic parameters have shown normalisation within a few days, indicating that the cerebral circulatory differences are transitory $[44,46,47]$.

Several Doppler measurements for CBF velocity (including the peak systolic velocity and time-averaged maximum velocity) have been used to investigate CBF in IUGR, as flow velocity changes of the MCA have been shown to correlate well with changes in CBF [48]. Contrasting results, however, have been reported [45, 49-51]. Blood flow velocity is not only influenced by flow volume and vessel diameter, but also by other factors such as haematocrit and vessel wall elastic properties [52]. It is well known that neonates who were exposed to chronic hypoxia in utero can present with polycythaemia. Increased haematocrit was also reported in some of the studies mentioned previously $[46,47,49]$. Moreover, changes in vessel wall composition could potentially occur in IUGR [39]. 
These factors, in combination with various types of measurements for blood flow velocity, have most likely confounded the results and led to the discrepancies among the reports. It is important to note that these factors, especially the higher blood viscosity and increased oxygen carrying capacity, could potentially confound all studies reporting on cerebral haemodynamics and oxygenation, which makes it difficult to interpret and compare results.

\section{What Is Protected by Brain-Sparing?}

Thus far we have referred to brain-sparing as a protective mechanism. It is important to note that recent research has challenged this conventional idea. Several studies in both term and preterm populations have demonstrated that IUGR subjects with brain-sparing show worse neurodevelopmental and behavioural outcomes than IUGR subjects without signs of brain-sparing and controls [53-58]. Although not all authors have confirmed this association [59-61], these findings imply that brain-sparing may not always protect against neurological damage [57]. Based on these studies it has even been proposed that increased CBF reflects advancing stages of brain injury; not a protective mechanism against it $[54,55,57]$. As described previously, IUGR may be associated with vascular remodelling and reduced vasoreactivity $[18,39-42]$. The increased CBF may in part be a direct consequence of disturbed circulatory regulation. This theory is supported by the finding that $\mathrm{CBF}$ remains elevated after birth, whilst the neonate is no longer exposed to a hypoxic environment and is no longer in need of a compensatory increase in CBF [43-47]. Hypothetically, postnatal continuation of increased CBF could cause hyperoxia within the fragile brain, which may contribute to neurological damage [62-64].

It is of great clinical significance that the nature of the brain-sparing phenomenon is further investigated, as new perspectives on this topic may have important implications for obstetric management of IUGR pregnancies.

\section{Cerebral Autoregulation}

Autoregulation is the ability of the cerebral vasculature to maintain fairly constant CBF despite fluctuations in cerebral perfusion pressure which are mainly affected by changes in systemic blood pressure $[65,66]$. When systemic blood pressure increases, cerebral arterioles constrict to prevent hyperperfusion of the brain. A decrease in blood pressure is compensated for by dilation of the cerebral vessels to prevent hypoperfusion and ischaemia. Autoregulation is thought to partially rely on a myogenic reflex, where smooth muscle cells in the arterioles contract or dilate depending on the intravascular pressure $[65,66]$. Other factors that influence the regulation of CBF include oxygen and carbon dioxide concentrations, metabolic demand, and neuronal influences $[65,66]$.

The ability to autoregulate appears to increase with gestational age. It is thought that autoregulation is impaired in sick preterm neonates, and it is believed that this contributes to the ischaemic and haemorrhagic injury frequently observed in this population [65]. As IUGR fetuses are often delivered preterm, they are theoretically at risk of impaired autoregulation. Due to vascular structural and functional changes, their autoregulation may be further compromised and IUGR neonates may thus be even less equipped than their AGA peers to cope with hypo- and hypertensive circumstances. In contrast, Bauer et al. $[67,68]$ found that low-birth-weight piglets exhibited a more adequate autoregulatory response to haemorrhagic hypotension and also higher brain oxygen extraction during hypercapnic hypoxia than their AGA peers. These results suggest that chronic intrauterine hypoxia may in fact stimulate the maturation of protective mechanisms to ensure adequate brain oxygenation and perfusion. In this case, IUGR subjects may actually be able to withstand periods of hypoperfusion and hypoxia better than their AGA counterparts. It is important to note, however, that these piglets were harvested from uncomplicated pregnancies. Although asymmetric growth of these piglets does suggest that brain-sparing and thus a certain degree of intrauterine oxygen deprivation was present, the haemodynamic disturbances and hypoxia may have been mild.

Despite its clinical significance, literature on this topic is extremely scarce and, to date, no studies have been performed investigating cerebral autoregulation in human IUGR neonates.

\section{Hypotension and Persistent Ductus Arteriosus}

Hypotension and a haemodynamically significant persistent ductus arteriosus (HSPDA) are both believed to negatively influence CBF in AGA preterm infants [69, 70]. As discussed above, besides prematurity, cerebral vascular wall changes could reduce vasoreactivity and thus limit the autoregulatory response to protect the IUGR brain against hypoperfusion under these circumstances. Moreover, the autoregulatory response is limited 
by the maximal dilation of the vessels [65]. In case of prolonged brain-sparing due to chronic hypoxaemia, maximal vessel dilatation may have already been reached, which would further limit the protective response to hypotension and HSPDA. Additionally, systemic vasoconstriction related to blood flow redistribution might still be in place, compromising the vasoconstrictor response to increase peripheral resistance in an attempt to raise blood pressure. Furthermore, cardiac dysfunction has been reported in IUGR neonates, which may also limit compensatory responses $[32,71]$. For example, IUGR neonates can present with diastolic dysfunction, restricting ventricular filling $[32,71]$. The tachycardiac response to hypotension would not be successful under these circumstances, as the increased heart rate would allow even less time for already diminished ventricular filling, further compromising cardiac output [72].

In contrast, animal work by Bauer et al. $[67,68]$ has suggested that exposure to chronic (mild) intrauterine hypoxia may actually improve autoregulation and cerebral oxygen extraction, allowing the IUGR brain to better withstand the effects of hypotension and HSPDA. It could also be argued that postnatal persistence of increased CBF may reduce the impact of systemic hypotension or ductal steal on the cerebral circulation. However, as postnatally increased $\mathrm{CBF}$ appears to be a temporary phenomenon only lasting a few days, and vascular functional and structural abnormalities may persist, protection against cerebral hypoperfusion may not be guaranteed beyond this period. Despite its clinical importance, we have little understanding of the impact of presumed hypotension and HSPDA on the postnatal haemodynamics of IUGR redistributing neonates. It is of major clinical importance that these topics are addressed in future studies, as results may have a significant impact on neonatal management, especially since HSPDA appears to occur more frequently and at an earlier time point in IUGR neonates compared to their AGA peers [73] and the HSPDA diameter has also been found to be larger in IUGR neonates [73]. It is unclear why the occurrence and size of HSPDA is increased in IUGR, but it may be related to vascular wall changes which have been observed on histology of the ductus arteriosus in this population [74].

\section{Intracranial Haemorrhage}

Intracranial haemorrhage $(\mathrm{ICH})$ is a common complication related to prematurity. A study by Alderliesten et al. [75] has shown that preterm neonates who develop severe peri-intraventricular haemorrhage show signs of cerebral hyperperfusion and suboptimal cerebral autoregulation. Thus, postnatal continuation of increased CBF $[46,47]$ in combination with potential loss of cerebral autoregulation $[18,65]$ and increased blood-brain barrier permeability [41] could make the preterm IUGR brain especially vulnerable to haemorrhagic insults. In fact, a sheep model of IUGR demonstrated highly reduced perivascular astrocytes and pericyte coverage of the microvasculature in several brain regions, including the germinal matrix [41]. These histologic changes are believed to result in decreased stability of the cerebral microvasculature and are linked to ICH $[41,76]$. Moreover, IUGR neonates appear to have higher blood pressures compared to their AGA peers $[32,33,71]$, theoretically further contributing to ICH risk.

Two recent studies have demonstrated a positive association between prenatal signs of brain-sparing and ICH $[77,78]$. In their large prospective study of 90 IUGR subjects, Cruz-Martinez et al. [77] found that IUGR neonates with an abnormal prenatal MCA-PI presented with ICH significantly more often than their non-brain-sparing counterparts and controls. In the study by Ertan et al. [78], although prenatal Doppler data were available for only a subgroup of neonates, the MCA-RI appeared to be lower in their ICH group. Contrastingly, others failed to demonstrate an association between brain-sparing and $\mathrm{ICH}$. Although gestational age differences may have confounded the results of several studies reporting on this topic [79-81], two studies in which gestational age was accounted for found no correlation between brain-sparing and ICH $[82,83]$. According to these studies, brainsparing does not increase the risk of haemorrhagic brain lesions. One study even found a reduced risk of ICH when the MCA-PI was decreased [84]. Some authors have therefore proposed that the adaptations to chronic in utero hypoxia may have accelerated maturation of autoregulatory mechanisms, thus protecting against ICH [85].

The underlying pathology to ICH appears to be complex and multifactorial, but it has been proposed that $\mathrm{ICH}$ occurs after a period of cerebral hypoperfusion with subsequent reperfusion $[86,87]$. Hypothetically, increased cardiac output and brain-sparing in IUGR may prevent cerebral hypoperfusion and protect the IUGR neonate against ICH. As discussed previously, however, 'brainsparing' may not be a (fully) protective mechanism. Haemodynamic instability and vascular remodelling may occur with long-standing or severe IUGR, which could impose a risk on the fragile preterm IUGR brain. Contrasting results from the studies mentioned previously may thus 
not only be explained by technical differences (various definitions, methods and timing to detect brain-sparing and $\mathrm{ICH}$ ) or confounders (gestational age, influence of clinical management), but may also rely on the severity of IUGR and fetal compromise.

In conclusion, the current literature shows conflicting results and cannot exclude negative consequences of brainsparing on the fragile cerebral vasculature. It is of great clinical importance that this topic is explored further.

\section{Cerebral Oxygenation to Guide Clinical Management}

Although hypo- and hypertension are thought to be harmful for the preterm brain, the actual blood pressure range that ensures adequate brain perfusion is unknown [70]. Also, the absolute blood pressure values may not correlate with cerebral perfusion $[88,89]$. Interestingly, cerebral oxygenation has been shown to predict neurodevelopmental outcome better than the presence of hypotension defined by absolute blood pressure values [90]. Moreover, fluctuations of cerebral oxygenation and oxygen extraction have been related to the occurrence of ICH $[75,87]$. It has therefore been proposed to consider measurements of cerebral perfusion rather than absolute blood pressure values as a basis for neonatal management $[88,90]$. Cerebral oxygenation indices as obtained with near-infrared spectroscopy have been proposed as a useful tool for routine clinical monitoring [90]. As IUGR neonates show different cerebral haemodynamics than AGA peers, they form a separate group within the premature NICU population. They will require a different approach with regard to the interpretation of cerebral oxygenation measurements and may need their own reference curves.

\section{Conclusion}

Chronic intrauterine hypoxia and prenatal haemodynamic disturbances appear to cause structural and functional changes in the cerebral circulation. These intrauterine adaptations appear to persist postnatally, and the cerebral circulation of IUGR neonates is thus different from their AGA peers during at least the first few days of life. However, the literature on this topic is extremely scarce and the existing literature shows many controversies. Therefore, the clinical consequences of these altered cerebral haemodynamics are poorly understood. It is thus challenging to predict which fetuses are at greatest risk of adverse outcomes, and we currently have little understanding regarding the most appropriate cerebral monitoring and management strategies for IUGR fetuses and neonates. An international initiative addressing these issues would be of great importance to improve the care for especially the preterm IUGR population.

\section{Acknowledgment}

A scholarship was provided to Emily Cohen by SIDS and Kids Australia.

\section{References}

- Spinillo A, Gardella B, Bariselli S, Alfei A, Silini EM, Bello BD: Cerebroplacental Doppler ratio and placental histopathological features in pregnancies complicated by fetal growth restriction. J Perinat Med 2014;42:321-328.

-2 Severi FM, Rizzo G, Bocchi C, D’Antona D, Verzuri MS, Arduini D: Intrauterine growth retardation and fetal cardiac function. Fetal Diag Ther 2000;15:8-19.

3 Hernandez-Andrade E, Figueroa-Diesel $\mathrm{H}$, Jansson T, Rangel-Nava H, Gratacos E: Changes in regional fetal cerebral blood flow perfusion in relation to hemodynamic deterioration in severely growth-restricted fetuses. Ultrasound Obstet Gynecol 2008;32:7176.

4 Robson S, Martin W, Morris R (eds): The Investigation and Management of the Small-forGestational-Age Fetus, Green-Top Guideline
No. 312013. 2013. https://www.rcog.org.uk/ en/guidelines-research-services/guidelines/ $\operatorname{gtg} 31 /$.

$\checkmark 5$ Cruz-Martinez R, Figueras F, Hernandez-Andrade E, Puerto B, Gratacos E: Longitudinal brain perfusion changes in near-term smallfor-gestational-age fetuses as measured by spectral Doppler indices or by fractional moving blood volume. Am J Obstet Gynecol 2010; 203:42.e1-6.

6 Benavides-Serralde A, Scheier M, Cruz-Martinez R, Crispi F, Figueras F, Gratacos E, et al: Changes in central and peripheral circulation in intrauterine growth-restricted fetuses at different stages of umbilical artery flow deterioration: new fetal cardiac and brain parameters. Gynecol Obstet Invest 2011;71:274-280.

7 Figueroa-Diesel H, Hernandez-Andrade E, Acosta-Rojas R, Cabero L, Gratacos E: Doppler changes in the main fetal brain arteries at different stages of hemodynamic adaptation in severe intrauterine growth restriction. Ultrasound Obstet Gynecol 2007;30:297-302.

-8 Dubiel M, Gunnarsson GO, Gudmundsson S: Blood redistribution in the fetal brain during chronic hypoxia. Ultrasound Obstet Gynecol 2002;20:117-121.

-9 Flood K, Unterscheider J, Daly S, Geary MP Kennelly MM, McAuliffe FM, et al: The role of brain sparing in the prediction of adverse outcomes in intrauterine growth restriction: results of the multicenter PORTO Study. Am J Obstet Gynecol 2014;211:288.e1-e5.

10 Bahado-Singh RO, Kovanci E, Jeffres A, Oz U, Deren O, Copel J, et al: The Doppler cerebroplacental ratio and perinatal outcome in intrauterine growth restriction. Am J Obstet Gynecol 1999;180:750-756. 
-11 Odibo AO, Riddick C, Pare E, Stamilio DM, Macones GA: Cerebroplacental Doppler ratio and adverse perinatal outcomes in intrauterine growth restriction: evaluating the impact of using gestational age-specific reference values. J Ultrasound Med 2005;24:1223-1228.

\12 Gramellini D, Folli MC, Raboni S, Vadora E, Merialdi A: Cerebral-umbilical Doppler ratio as a predictor of adverse perinatal outcome. Obstet Gynecol 1992;79:416-420.

13 Habek D, Salihagic A, Jugovic D, Herman R: Doppler cerebro-umbilical ratio and fetal biophysical profile in the assessment of peripartal cardiotocography in growth-retarded fetuses. Fetal Diagn Ther 2007;22:452-456.

$\checkmark 14$ Habek D, Hodek B, Herman R, Jugovic D, Cerkez Habek J, Salihagic A: Fetal biophysical profile and cerebro-umbilical ratio in assessment of perinatal outcome in growth-restricted fetuses. Fetal Diagn Ther 2003;18:12-16.

15 Murata S, Nakata M, Sumie M, Sugino N: The Doppler cerebroplacental ratio predicts nonreassuring fetal status in intrauterine growth restricted fetuses at term. J Obstet Gynaecol Res 2011;37:1433-1437.

16 Cruz-Martinez R, Figueras F, Hernandez-Andrade E, Oros D, Gratacos E: Fetal brain Doppler to predict cesarean delivery for nonreassuring fetal status in term small-for-gestational-age fetuses. Obstet Gynecol 2011;117: 618-626.

17 Konje JC, Bell SC, Taylor DJ: Abnormal Doppler velocimetry and blood flow volume in the middle cerebral artery in very severe intrauterine growth restriction: is the occurence of reversal of compensatory flow too late? BJOG 2001;108:973-979.

- 18 Fignon A, Salihagic A, Akoka S, Moraine C, Lansac J, Laurini R, et al: Twenty-day cerebral and umbilical Doppler monitoring on a growth retarded and hypoxic fetus. Eur J Obstet Gynecol Reprod Biol 1996;66:83-86.

19 Vyas S, Nicolaides KH, Bower S, Campbell S: Middle cerebral artery flow velocity waveforms in fetal hypoxaemia. Br J Obstet Gynaecol 1990;97:797-803.

20 Laurini RN: Fetal brain pathology and ultrasound; in Chervenak FA, Kurjak A, Comstock $\mathrm{CH}$ (eds): Ultrasound and the Fetal Brain (Progress in Obstetric and Gynecological Sonography series). New York, Parthenon Publishing Group, 1995, pp 27-42.

21 Laurini RN, Arbeille B: Hypoxic-ischemic damage to the brain in the human fetus; in Arbeille P, Maulik D (eds): Fetal Hypoxia (Progress in Obstetric and Gynecological Sonography series). New York, Parthenon Publishing Group, 1999, pp 1-14.

-22 Figueroa-Diesel H, Hernandez-Andrade E, Benavides-Serralde A, Crispi F, Acosta-Rojas $\mathrm{R}$, Cabero L, et al: Cerebral venous blood flow in growth restricted fetuses with an abnormal blood flow in the umbilical artery before 32 weeks of gestation. Eur J Obstet Gynecol Reprod Biol 2008;140:201-205.
3 Dubiel M, Breborowicz GH, Laurini R, Gudmundsson S: Blood velocity in the fetal vein of Galen and the outcome of high-risk pregnancy. Eur J Obstet Gynecol Reprod Biol 2001;99: 14-18.

24 Baschat AA, Hecher K: Fetal growth restriction due to placental disease. Semin Perinatol 2004; 28:67-80.

25 Dodson RB, Rozance PJ, Petrash CC, Hunter KS, Ferguson VL: Thoracic and abdominal aortas stiffen through unique extracellular matrix changes in intrauterine growth restricted fetal sheep. Am J Physiol Heart Circ Physiol 2014;306:H429-H437.

26 Thompson JA, Richardson BS, Gagnon R, Regnault TR: Chronic intrauterine hypoxia interferes with aortic development in the late gestation ovine fetus. J Physiol 2011;589:33193332.

27 Akira M, Yoshiyuki S: Placental circulation, fetal growth, and stiffness of the abdominal aor ta in newborn infants. J Pediatr 2006;148:4953.

28 Cosmi E, Visentin S, Fanelli T, Mautone AJ, Zanardo V: Aortic intima media thickness in fetuses and children with intrauterine growth restriction. Obstet Gynecol 2009;114:11091114.

29 Cruz-Lemini M, Crispi F, Valenzuela-Alcaraz B, Figueras F, Gomez O, Sitges M, et al: A fetal cardiovascular score to predict infant hypertension and arterial remodeling in intrauterine growth restriction. Am J Obstet Gynecol 2014; 210:552.e1-e22.

30 Koklu E, Kurtoglu S, Akcakus M, Koklu S, Buyukkayhan D, Gumus $\mathrm{H}$, et al: Increased aortic intima-media thickness is related to lipid profile in newborns with intrauterine growth restriction. Horm Res 2006;65:269275.

31 Koklu E, Ozturk MA, Kurtoglu S, Akcakus M, Yikilmaz A, Gunes T: Aortic intima-media thickness, serum IGF-I, IGFBP-3, and leptin levels in intrauterine growth-restricted newborns of healthy mothers. Pediatr Res 2007;62: 704-709.

32 Sehgal A, Doctor T, Menahem S: Cardiac function and arterial biophysical properties in small for gestational age infants: postnatal manifestations of fetal programming. J Pediatr 2013;163:1296-1300.

33 Sehgal A, Doctor T, Menahem S: Cardiac function and arterial indices in infants born small for gestational age: analysis by speckle tracking. Acta Paediatr 2014;103:e49-e54.

34 Skilton MR, Evans N, Griffiths KA, Harmer JA, Celermajer DS: Aortic wall thickness in newborns with intrauterine growth restriction. Lancet 2005;365:1484-1486.

35 Langille BL: Arterial remodeling: relation to hemodynamics. Can J Physiol Pharmacol 1996;74:834-841.

36 Martyn CN, Barker DJ, Osmond C: Mothers' pelvic size, fetal growth, and death from stroke and coronary heart disease in men in the UK. Lancet 1996;348:1264-1268.
37 Law CM, Shiell AW: Is blood pressure inversely related to birth weight? The strength of evidence from a systematic review of the literature. J Hypertens 1996;14:935-941.

- 38 Godfrey KM, Barker DJ: Fetal programming and adult health. Public Health Nutr 2001;4: 611-624.

-39 Longo LD, Pearce WJ: Fetal cerebrovascular acclimatization responses to high-altitude, long-term hypoxia: a model for prenatal programming of adult disease? Am J Physiol Regul Integr Comp Physiol 2005;288:R16-R24.

40 Pearce W: Hypoxic regulation of the fetal cerebral circulation. J Appl Physiol 2006;100:731738.

41 Castillo-Melendez M, Yawno T, Allison BJ, Jenkin G, Wallace EM, Miller SL: Cerebrovascular adaptations to chronic hypoxia in the growth restricted lamb. Int J Dev Neurosci 2015, Epub ahead of print.

42 Arduini D, Rizzo G, Romanini C, Mancuso S: Fetal haemodynamic response to acute maternal hyperoxygenation as predictor of fetal distress in intrauterine growth retardation. BMJ 1989;298:1561-1562.

43 Nishimaki S, Shima Y, Yoda H, Kawakami T, Akamatsu H: Blood flow velocities in the cerebral arteries and descending aorta in small-fordates infants. Pediatr Radiol 1993;23:575-577.

44 van Bel F, van de Bor M, Stijnen T, Ruys JH Decreased cerebrovascular resistance in small for gestational age infants. Eur J Obstet Gynecol Reprod Biol 1986;23:137-144.

45 Ley D, Marsal K: Doppler velocimetry in cerebral vessels of small for gestational age infants. Early Hum Dev 1992;31:171-180.

-46 Baenziger O, Jaggi JL, Mueller AC, Morales CG, Lipp HP, Lipp AE, et al: Cerebral blood flow in preterm infants affected by sex, mechanical ventilation, and intrauterine growth. Pediatr Neurol 1994;11:319-324.

47 Ishii H, Takami T, Fujioka T, Mizukaki N, Kondo A, Sunohara D, et al: Comparison of changes in cerebral and systemic perfusion between appropriate- and small-for-gestationalage infants during the first three days after birth. Brain Dev 2014;36:380-387.

48 Clark JM, Skolnick BE, Gelfand R, Farber RE, Stierheim M, Stevens WC, et al: Relationship of 133Xe cerebral blood flow to middle cerebral arterial flow velocity in men at rest. J Cereb Blood Flow Metab 1996;16:1255-1262.

-49 Guajardo CD, Mandelbaum V, Linderkamp O: Cardiac output and cerebral blood flow velocity in small for gestational age infants during the first 5 days after birth. Early Hum Dev 1994;37:187-193.

50 Kempley ST, Gamsu HR, Vyas S, Nicolaides K: Effects of intrauterine growth retardation on postnatal visceral and cerebral blood flow velocity. Arch Dis Child 1991;66:1115-1118.

- 51 Basu S, Dewangan S, Barman S, Shukla RC, Kumar A: Postnatal changes in cerebral blood flow velocity in term intra-uterine growth-restricted neonates. Paediatr Int Child Health 2014;34:189-193. 
52 Missaridis TX, Shung KK: The effect of hemodynamics, vessel wall compliance and hematocrit on ultrasonic Doppler power: an in vitro study. Ultrasound Med Biol 1999;25:549-559.

53 Cruz-Martinez R, Figueras F, Oros D, Padilla $\mathrm{N}$, Meler E, Hernandez-Andrade E, et al: Cerebral blood perfusion and neurobehavioral performance in full-term small-for-gestationalage fetuses. Am J Obstet Gynecol 2009;201: 474.e1-e7.

- 54 Eixarch E, Meler E, Iraola A, Illa M, Crispi F, Hernandez-Andrade E, et al: Neurodevelopmental outcome in 2-year-old infants who were small-for-gestational age term fetuses with cerebral blood flow redistribution. Ultrasound Obstet Gynecol 2008;32:894-899.

55 Figueras F, Cruz-Martinez R, Sanz-Cortes M, Arranz A, Illa M, Botet F, et al: Neurobehavioral outcomes in preterm, growth-restricted infants with and without prenatal advanced signs of brain-sparing. Ultrasound Obstet Gynecol 2011;38:288-294.

56 Oros D, Figueras F, Cruz-Martinez R, Padilla $\mathrm{N}$, Meler E, Hernandez-Andrade E, et al: Middle versus anterior cerebral artery Doppler for the prediction of perinatal outcome and neonatal neurobehavior in term small-for-gestational-age fetuses with normal umbilical artery Doppler. Ultrasound Obstet Gynecol 2010;35: 456-461.

-57 Roza SJ, Steegers EA, Verburg BO, Jaddoe VW, Moll HA, Hofman A, et al: What is spared by fetal brain-sparing? Fetal circulatory redistribution and behavioral problems in the general population. Am J Epidemiol 2008;168:11451152.

58 Murray E, Fernandes M, Fazel M, Kennedy SH, Villar J, Stein A: Differential effect of intrauterine growth restriction on childhood neurodevelopment: a systematic review. BJOG 2015;122:1062-1072.

-59 Scherjon SA, Oosting H, Smolders-DeHaas H, Zondervan HA, Kok JH: Neurodevelopmental outcome at three years of age after fetal 'brainsparing'. Early Hum Dev 1998;52:67-79.

-60 Scherjon SA, Smolders-DeHaas H, Kok JH, Zondervan HA: The 'brain-sparing' effect: antenatal cerebral Doppler findings in relation to neurologic outcome in very preterm infants. Am J Obstet Gynecol 1993;169:169-175.

-61 van den Broek AJ, Kok JH, Houtzager BA, Scherjon SA: Behavioural problems at the age of eleven years in preterm-born children with or without fetal brain sparing: a prospective cohort study. Early Hum Dev 2010;86:379-384.

-62 Felderhoff-Mueser U, Bittigau P, Sifringer M, Jarosz B, Korobowicz E, Mahler L, et al: Oxygen causes cell death in the developing brain. Neurobiol Dis 2004;17:273-282.

63 Gerstner B, DeSilva TM, Genz K, Armstrong A, Brehmer F, Neve RL, et al: Hyperoxia causes maturation-dependent cell death in the developing white matter. J Neurosci 2008;28:12361245.
64 Yis U, Kurul SH, Kumral A, Cilaker S, Tugyan $\mathrm{K}$, Genc S, et al: Hyperoxic exposure leads to cell death in the developing brain. Brain Dev 2008;30:556-562.

65 Brew N, Walker D, Wong FY: Cerebral vascular regulation and brain injury in preterm infants. Am J Physiol Regul Integr Comp Physiol 2014;306:R773-R786.

66 Greisen G: Autoregulation of cerebral blood flow in newborn babies. Early Hum Dev 2005; 81:423-428.

67 Bauer R, Walter B, Brandl U: Intrauterine growth restriction improves cerebral $\mathrm{O}_{2}$ utilization during hypercapnic hypoxia in newborn piglets. J Physiol 2007;584:693-704.

68 Bauer R, Walter B, Vollandt R, Zwiener U: Intrauterine growth restriction ameliorates the effects of gradual hemorrhagic hypotension on regional cerebral blood flow and brain oxygen uptake in newborn piglets. Pediatr Res 2004; 56:639-646.

69 Lemmers PM, Toet MC, van Bel F: Impact of patent ductus arteriosus and subsequent therapy with indomethacin on cerebral oxygenation in preterm infants. Pediatrics 2008;121: 142-147.

70 Short BL, Van Meurs K, Evans JR; Cardiology Group: Summary proceedings from the cardiology group on cardiovascular instability in preterm infants. Pediatrics 2006;117:S34-S39.

71 Fouzas S, Karatza AA, Davlouros PA, Chrysis D, Alexopoulos D, Mantagos S, et al: Neonatal cardiac dysfunction in intrauterine growth restriction. Pediatr Res 2014;75:651-657.

72 Vitarelli A, Gheorghiade M: Diastolic heart failure: standard Doppler approach and beyond. Am J Cardiol 1998;81:115G-121G.

73 Rakza T, Magnenant E, Klosowski S, Tourneux P, Bachiri A, Storme L: Early hemodynamic consequences of patent ductus arteriosus in preterm infants with intrauterine growth restriction. J Pediatr 2007;151:624-628.

74 Ibara S, Tokunaga M, Ikenoue T, Murata Y, Hirano T, Asano H, et al: Histologic observation of the ductus arteriosus in premature infants with intrauterine growth retardation. J Perinatol 1994;14:411-416.

75 Alderliesten T, Lemmers PM, Smarius JJ, van de Vosse RE, Baerts W, van Bel F: Cerebral oxygenation, extraction, and autoregulation in very preterm infants who develop peri-intraventricular hemorrhage. J Pediatr 2013;162: 698-704 e2.

76 Ballabh P: Intraventricular hemorrhage in premature infants: mechanism of disease. Pediatr Res 2010;67:1-8.

77 Cruz-Martinez R, Tenorio V, Padilla N, Crispi F, Figueras F, Gratacos E: Risk of neonatal brain ultrasound abnormalities in intrauterine growth restricted fetuses born between 28 and 34 weeks: relationship with gestational age at birth and fetal Doppler. Ultrasound Obstet Gynecol 2015, Epub ahead of print.
78 Ertan AK, Tanriverdi HA, Meier M, Schmidt W: Perinatal risk factors for neonatal intracerebral hemorrhage in preterm infants. Eur J Obstet Gynecol Reprod Biol 2006;127:2934.

79 Marsoosi V, Bahadori F, Esfahani F, GhasemiRad M: The role of Doppler indices in predicting intra ventricular hemorrhage and perinatal mortality in fetal growth restriction. Med Ultrason 2012;14:125-132.

80 Maunu J, Ekholm E, Parkkola R, Palo P, Rikalainen $\mathrm{H}$, Lapinleimu $\mathrm{H}$, et al: Antenatal Doppler measurements and early brain injury in very low birth weight infants. J Pediatr 2007; 150:51-56.e1.

81 Scherjon SA, Oosting H, Kok JH, Zondervan HA: Effect of fetal brainsparing on the early neonatal cerebral circulation. Arch Dis Child Fetal Neonatal Ed 1994;71:F11-F15.

82 Baschat AA, Gembruch U, Viscardi RM, Gortner L, Harman CR: Antenatal prediction of intraventricular hemorrhage in fetal growth restriction: what is the role of Doppler? Ultrasound Obstet Gynecol 2002;19:334-339.

83 Sterne G, Shields LE, Dubinsky TJ: Abnormal fetal cerebral and umbilical Doppler measurements in fetuses with intrauterine growth restriction predicts the severity of perinatal morbidity. J Clin Ultrasound 2001;29:146-151.

84 Mari G, Abuhamad AZ, Keller M, Verpairojkit B, Ment L, Copel JA: Is the fetal brain-sparing effect a risk factor for the development of intraventricular hemorrhage in the preterm infant? Ultrasound Obstet Gynecol 1996;8:329332.

85 Amato M, Konrad D, Huppi P, Donati F: Impact of prematurity and intrauterine growth retardation on neonatal hemorrhagic and ischemic brain damage. Eur Neurol 1993;33:299_ 303.

86 Noori S, Seri I: Hemodynamic antecedents of peri/intraventricular hemorrhage in very preterm neonates. Semin Fetal Neonatal Med 2015, Epub ahead of print.

87 Noori S, McCoy M, Anderson MP, Ramji F, Seri I: Changes in cardiac function and cerebral blood flow in relation to peri/intraventricular hemorrhage in extremely preterm infants. J Pediatr 2014;164:264-270.e1-e3.

88 Bonestroo HJ, Lemmers PM, Baerts W, van Bel F: Effect of antihypotensive treatment on cerebral oxygenation of preterm infants without PDA. Pediatrics 2011;128:e1502-e1510.

89 Kooi EM, van der Laan ME, Verhagen EA, Van Braeckel KN, Bos AF: Volume expansion does not alter cerebral tissue oxygen extraction in preterm infants with clinical signs of poor perfusion. Neonatology 2013;103:308-314.

90 Alderliesten T, Lemmers PM, van Haastert IC, de Vries LS, Bonestroo HJ, Baerts W, et al: Hypotension in preterm neonates: low blood pressure alone does not affect neurodevelopmental outcome. J Pediatr 2014;164:986-991. 